\title{
Low-income consumers' attitudes and behaviour towards access, availability and motivation to eat fruit and vegetables
}

\author{
LA Dibsdall*, N Lambert, RF Bobbin and LJ Frewer \\ Institute of Food Research, Norwich Research Park, Colney, Norwich, NR4 7UA, UK
}

Submitted 27 May 2002: Accepted 5 September 2002

\begin{abstract}
Objective: To determine low-income consumers' attitudes and behaviour towards fruit and vegetables, in particular issues of access to, affordability of and motivation to eat fruit and vegetables.

Design and setting: Questionnaire survey mailed to homes owned by a large UK housing association.

Participants: Participants were 680 low-income men and women, aged 17-100 years. Results: Age, employment, gender, smoking and marital status all affected attitudes towards access, affordability and motivation to eat fruit and vegetables. Few (7\%) participants experienced difficulty in visiting a supermarket at least once a week, despite nearly half having no access to a car for shopping. Fruit and vegetables were affordable to this low-income group in the amounts they habitually bought; purchasing additional fruits and vegetables was seen as prohibitively expensive. Less than $5 \%$ felt they had a problem with eating healthily and yet only $18 \%$ claimed to eat the recommended 5 or more portions of fruit and vegetables every day.

Conclusions: Supported by research, current UK Government policy is driven by the belief that low-income groups have difficulties in access to and affordability of fruit and vegetables. Findings from this particular group suggest that, of the three potential barriers, access and affordability were only a small part of the 'problem' surrounding low fruit and vegetable consumption. Thus, other possible determinants of greater consequence need to be identified. We suggest focusing attention on motivation to eat fruit and vegetables, since no dietary improvement can be achieved if people do not recognise there is a problem.
\end{abstract}

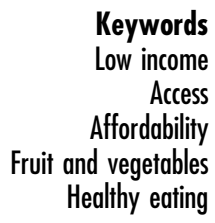

Keywords ow income Access and vegetables Healthy eating
Inappropriate nutrition is a significant causative factor for many of the chronic diseases currently afflicting developed countries, namely cancers, heart disease and type 2 diabetes $^{1,2}$. As a result, national and international health bodies have focused increasing effort in recent years on defining and promoting healthy diets ${ }^{3}$. It is commonly accepted that a diet rich in fruit and vegetables (F\&V) can reduce the risk of most cancers and heart disease $\mathrm{e}^{4}$. Consequently, increasing the consumption of $\mathrm{F} \& \mathrm{~V}$ to at least 5 portions per day features prominently in public health nutrition strategies ${ }^{5,6}$.

Low-income groups (LIGs) have a greater tendency to consume unhealthy diets and develop chronic diseases at an earlier age, compared with higher socio-economic groups $^{7-9}$. Improving the diets of LIGs is a priority in recent UK Government public health policies and focuses largely on improving access to and affordability of a healthy diet ${ }^{10}$. In the UK, households earning less than $£ 150$ per week are least likely to have adequate nutritional intakes ${ }^{11}$. As well as limited money to pay for wholesome foods ${ }^{12,13}$, it is claimed that LIGs suffer disproportionately from problems surrounding access to healthy food ${ }^{14}$, social support, perishability, lack of cooking skills and a lack of nutritional knowledge $\mathrm{e}^{15,16}$.

Campaigns to tackle food poverty, such as those developed by Sustain ${ }^{17}$ (formerly the National Food Alliance) and the Rowntree Foundation ${ }^{18}$, have largely focused on deprived inner-city areas. Large networks of streets and estates make it difficult for tenants to gain access to inexpensive, good-quality food ${ }^{19}$. Community food co-operatives have been developed in some of these areas to address this issue of access to healthy diets ${ }^{20}$. Training in food and nutrition, and developing skills such as menu planning, budgeting, food storage and cooking for low-income families has been provided in other areas by the UK Expanded Food and Nutrition Education Programme $^{21}$, which has been in use in the USA for many years $^{22}$. Despite this effort, LIGs continue to be more at risk from diet-related diseases.

Home ownership is a key criterion used in assessing socio-economic status in the UK. Social housing, comprising stock rented from local authorities or registered social 
landlords, accounts for $20 \%$ of all properties in the $\mathrm{UK}^{23}$. Most tenants in these categories of properties are in receipt of some form of social benefit ${ }^{23}$ and represent a substantial subgroup of the low-income demographic. They have not previously been the focus of food poverty research. The Institute of Food Research has developed a research programme with Broadland Housing Association (3500 homes) to investigate the attitudes and behaviours of tenants towards various food and health issues using both qualitative and quantitative methodologies ${ }^{24}$.

In-depth interviews with female tenants from Broadland Housing Association produced a detailed qualitative analysis of their attitudes and behaviours towards food and health (especially fruit, vegetables and cancer) ${ }^{24}$. Three key themes emerged:

1. the amount and complexity of information received on healthy eating;

2. individual differences with respect to upbringing, personal values and food habits; and

3. control issues related to personal health, food purchasing and dietary cravings.

Contrary to findings in other studies ${ }^{12,14}$, access to and affordability of wholesome food were not major issues for these women; they were all able to shop regularly at a large supermarket and were able to budget for their habitual intakes of F\&V. The aim of the present study was to explore these important observations in a quantitative manner across all of the tenants. The results will assist in the targeting of resources to those most in need and to identify the most salient barriers to eating a healthy diet.

\section{Methods}

\section{Questionnaire distribution}

Questionnaires were distributed in July/August 2001 to 3000 homes in East Anglia owned by Broadland Housing Association. This housing association provides homes to individuals and families on a low income and/or receiving social security support. The questionnaires formed an insert to the residents' normal quarterly newsletter and were directed towards the person who mainly did the food shopping in the household, rather than a named individual. Participants were provided with a freepost envelope in which to return their questionnaire.

\section{Participants}

Overall, there were 690 replies, equating to a $23 \%$ response rate; such a response is not uncommon for this sociodemographic population who is traditionally seen as difficult to engage in such studies ${ }^{12}$. Common difficulties faced by researchers studying LIGs include low functional literacy and numeracy rates, high levels of domestic chaos and stress and the constraints of the time-demanding and complex lives of LIGs ${ }^{12}$. As an incentive to participate, the participants were invited to enter a prize draw for $£ 100$ of home improvement vouchers. Of the responses, 10 were dropped from the analysis due to a high degree of missing information on the questionnaire, leaving a total of 680 participants. Those participants with fewer than 10 omissions were still included in the analyses as there was a sufficient sample size to achieve statistical significance. The total number of participants $(n)$ therefore differs for each questionnaire item.

\section{Questionnaire design}

The questionnaire was divided into two parts. In part one, participants were asked to rate their agreement with 30 questionnaire items on a Likert-type seven-point scale labelled strongly agree, moderately agree, slightly agree, neither agree nor disagree, strongly disagree, moderately disagree and slightly disagree. The scales were scored so that $1=$ strongly agree to $7=$ strongly disagree. Therefore calculated means greater or less than 4 indicated participants were tending to agree or disagree with a particular statement. Ten of these questionnaire items were designed to assess issues of accessibility to, 10 issues of affordability of and 10 issues of motivation to eat F\&V (Table 3 results lists the statements and highlights to which of the themes the statements belong). The three themes chosen were key areas identified during in-depth interviews with tenants from the same housing association during a previous study ${ }^{24}$. A total of 30 statements was chosen in order to be able to perform Principal Components Analysis (PCA) on the data with a suitable number of participants. The statements themselves were developed from ideas generated during these qualitative interviews and the guiding principles of questionnaires for this particular group. They were also based upon current beliefs and attitudes highlighted in studies with other $\mathrm{LIGs}^{8,14}$. It should be noted that the statements were designed to assess both attitude and behaviour, such that the form of the wording differed between statements. The readability of the questionnaire was cross-checked by the tenant participation officer of Broadland Housing Association, who has experience in distributing questionnaires appropriate to the literacy level of this population.

Part two of the questionnaire elicited demographic information about the participants, such as age, marital status, smoking status, employment status and number of helpings/portions of F\&V (excluding potatoes) participants claimed to eat per day (Tables 1 and 2). It was not the intention to measure 'actual' F\&V intakes, but to elicit the participant's perceptions of their diet. Consequently, 'portion' was not scientifically defined and 'helping', as suggested by Broadland Housing Association, was used as an alternative to the word 'portion' in order to aid participants in estimating their intake.

\section{Statistical analysis}

In order to reduce the data to sub-scales that could be used as dependent variables in further analysis, PCA was 
Table 1 Basic demographic characteristics of participants

\begin{tabular}{|c|c|c|}
\hline Characteristic & Frequency & $\%$ of total \\
\hline \multicolumn{3}{|l|}{ Gender } \\
\hline Female & 530 & 78 \\
\hline Male & 150 & 22 \\
\hline \multicolumn{3}{|l|}{ Age (years) } \\
\hline $17-30$ & 179 & 27 \\
\hline $31-50$ & 237 & 36 \\
\hline $51-70$ & 128 & 20 \\
\hline $71-100$ & 113 & 17 \\
\hline \multicolumn{3}{|l|}{ Marital status } \\
\hline Single & 180 & 28 \\
\hline Married/with partner & 214 & 33 \\
\hline Divorced/separated & 157 & 24 \\
\hline Widowed & 97 & 15 \\
\hline \multicolumn{3}{|c|}{ Number of adults in household } \\
\hline 1 & 451 & 66 \\
\hline 2 & 200 & 29 \\
\hline $3+$ & 29 & 4 \\
\hline \multicolumn{3}{|c|}{ Number of children in household } \\
\hline 0 & 370 & 57 \\
\hline 1 & 142 & 22 \\
\hline 2 & 100 & 15 \\
\hline $3+$ & 38 & 6 \\
\hline \multicolumn{3}{|l|}{ Employment status } \\
\hline Full time & 111 & 18 \\
\hline Part time & 97 & 16 \\
\hline Jobseeker & 69 & 11 \\
\hline Looking after family & 127 & 21 \\
\hline Retired & 167 & 27 \\
\hline On sick leave & 45 & 7 \\
\hline \multicolumn{3}{|l|}{ Location } \\
\hline Urban & 430 & 64 \\
\hline Suburban & 160 & 24 \\
\hline Rural & 83 & 12 \\
\hline
\end{tabular}

Table 2 Food and health characteristics of participants

\begin{tabular}{lcc}
\hline Characteristic & Frequency & \% of total \\
\hline Smoking & & \\
Smoker & 227 & 35 \\
Ex-smoker & 133 & 21 \\
Non-smoker & 287 & 44 \\
Illnesses* & & \\
None & 449 & 67 \\
Arthritis & 167 & 25 \\
Cancer & 28 & 4 \\
Coronary heart disease & 32 & 5 \\
Stroke & 18 & 3 \\
Portions of fruit and vegetables claimed to be eatent & \\
0-2 & 323 & 49 \\
$3-4$ & 216 & 33 \\
5+ & 115 & 18 \\
Types of food claimed to be eaten & & \\
Red meat & 478 & 70 \\
White meat & 587 & 86 \\
Fish & 534 & 79 \\
Organic food & 146 & 6 \\
Vegetarian & 38 & \\
\hline
\end{tabular}

* Some participants suffered from more than one illness.

†These values relate to participants' perceptions and not actual intake measures. conducted on the 30 attitude items in part one of the questionnaire. Examination of the scree plot suggested that the most likely number of factors to be extracted was between three and seven. Principal components with varimax rotation was used as the method of extraction and factor loadings less than 0.3 were suppressed in the analysis. The data grouped together into six sensibly interpretable factors, which were labelled as 'Choice', 'Health', 'Affordability', 'Change', 'Organic' and 'Transport'. Reducing all of the questionnaire items into these six factors explained $59.4 \%$ of the total variance. Reliability analysis, using Cronbach's alpha as a measure of internal consistency, was applied to see how well the different characteristics loading onto each component were measuring the same concept. The six new sub-scales were then created by calculating the mean of the responses to all the questionnaire items relating to that one factor for each person.

Multivariate analysis of variance (MANOVA) was performed to investigate the effect of demographic variables on attitudes towards $\mathrm{F} \& \mathrm{~V}$, as measured by the 'Choice', 'Health', 'Affordability', 'Change', 'Organic' and 'Transport' sub-scales. In all analyses, both multivariate and univariate effects were examined. Post hoc Tukey tests were conducted on the significant effects from the MANOVAs, the results of which are given in the means tables below.

Cross-tabulation analyses using Pearson's $\chi^{2}$ statistic were additionally performed on the number of portions participants claimed to eat for each relevant demographic variable identified from the previous analyses.

All analyses were conducted with SPSS statistical software (version 11.0), using a statistical significance level of 0.05 or less for all tests.

\section{Results}

\section{Participant characteristics}

Table 1 shows the basic demographic characteristics of the respondents. Most (78\%) of the participants were female, which reflects the fact that women were mostly responsible for doing the household food shopping. The mean age of the participants was $46.5 \pm 20.0$ years; nearly $63 \%$ of the total participants were aged between 17 and 50 years. Two-thirds of participants lived alone, being either single, divorced/separated from their partner or widowed. Proportionally more men (36\%) were single than women (25\%).

Only $18 \%$ of participants had a full-time job, the majority of which were manual/unskilled or manual/semi-skilled such as cooks, cleaners, delivery drivers, etc., consistent with being in an LIG. Males were significantly more represented in this category. In contrast, over $95 \%$ of those looking after the family were female. Twenty-seven per cent of the sample was retired, consistent with the age distribution of this sample. 


\section{Participants' bealth and food characteristics}

The population profile for characteristics linked to health and food is given in Table 2 . The frequency of smokers (35\%) is consistent with the national averages for LIGs ${ }^{25}$. Only $18 \%$ claimed to eat the recommended 5 or more portions of $F \& V$ per day: this is again consistent with national data for $\mathrm{LIGs}^{26}$ and supports the view that people on a low income tend to eat a diet that is significantly less than recommended in nutritional guidelines ${ }^{12}$. Half the sample claimed to eat only 2 or fewer portions of F\&V per day. Just over one in five claimed to eat some organic foods, which is interesting given that organically farmed produce is currently more expensive than conventional foods. The number of participants who classed themselves as vegetarians $(6 \%)$ is consistent with national figures for all demographic groups ${ }^{26}$.

\section{Principal components analysis}

Six factors were reduced from the PCA (Table 3). The first factor, 'Choice', consisted of questionnaire items related to the choice of shopping facilities, availability and choice of fresh, frozen or tinned F\&V. 'Health' related to how healthy participants perceive their diet to be. 'Affordability' related to the affordability of conventional and organically farmed produce. Motivation to change their diet for reasons of weight control or prevention of cancer grouped into the 'Change' factor. 'Organic' consisted of the two questionnaire items asking participants about their desire to eat more organic F\&V. All of these groupings had a high internal reliability (Cronbach's alpha $>0.78$ ). Method of transport to convey their shopping home, including bus, car, taxi or use of a delivery service, all loaded onto the 'Transport' factor, but did not have as high reliability $(\alpha=0.55)$. This lack of consistency is presumably due to participants choosing one mode of transport over another, rather than endorsing several modes. For example, those who did have access to a car for shopping purposes were less likely to use public transport.

\section{Variation in attitudes towards bealtby eating, access to and affordability of fruits and vegetables according to participant demographics}

Gender

MANOVA analysis indicated that men's and women's attitudes towards healthy eating differed significantly (Pillai's Trace $F(6,657)=2.605, P<0.05)$. However, the univariate $F$ was significant only for the 'Change' sub-scale $(F(1,662)=9.028, P<0.01)$. In other words,

Table 3 Questionnaire items loading onto each of the six factors reduced from Principal Components Analysis, and the measure of internal consistency for each factor (Cronbach's $\alpha$ )

\begin{tabular}{|c|c|c|c|c|}
\hline Factor & Questionnaire item & $\begin{array}{l}\text { Factor } \\
\text { loading }^{*}\end{array}$ & $\begin{array}{l}\text { Percentage } \\
\text { of variance } \\
\text { explained }\end{array}$ & Cronbach's $\alpha$ \\
\hline \multirow[t]{10}{*}{ Choice } & Where I shop has a wide choice of fresh vegetables (AC) & 0.85 & \multirow[t]{10}{*}{20.6} & \multirow[t]{10}{*}{0.87} \\
\hline & Where I shop has a wide choice of fresh fruit (AC) & 0.82 & & \\
\hline & Where I shop has a wide choice of frozen vegetables (AC) & 0.81 & & \\
\hline & Where I shop has a wide choice of tinned vegetables (AC) & 0.80 & & \\
\hline & Where I shop has a wide choice of tinned fruit (AC) & 0.78 & & \\
\hline & I am satisfied with the shop where I buy most of my food (MO) & 0.57 & & \\
\hline & I think vegetables are affordable to me in the shop where I buy most of my food (AF) & 0.53 & & \\
\hline & I think fruit is affordable to me in the shop where I buy most of my food (AF) & 0.50 & & \\
\hline & Visiting a supermarket is easy for me to do (AC) & 0.36 & & \\
\hline & There is a wide choice of food shops in my local area (AC) & 0.35 & & \\
\hline \multirow[t]{5}{*}{ Health } & I eat enough vegetables for my health (MO) & 0.84 & \multirow[t]{5}{*}{13.1} & \multirow[t]{5}{*}{0.83} \\
\hline & I eat enough fruit for my health (MO) & 0.83 & & \\
\hline & I eat healthily (MO) & 0.74 & & \\
\hline & I enjoy eating fruit (MO) & 0.63 & & \\
\hline & I enjoy eating vegetables (MO) & 0.61 & & \\
\hline \multirow[t]{5}{*}{ Affordability } & Buying more fruit than I already do would be difficult on my budget (AF) & 0.86 & \multirow[t]{5}{*}{7.5} & \multirow[t]{5}{*}{0.85} \\
\hline & Buying more vegetables than I already do would be difficult on my budget (AF) & 0.83 & & \\
\hline & I cannot afford to buy organic vegetables (AF) & 0.72 & & \\
\hline & I cannot afford to buy organic fruit (AF) & 0.72 & & \\
\hline & Lack of money prevents me from eating healthily (AF) & 0.66 & & \\
\hline \multirow[t]{4}{*}{ Change } & I would consider cutting out foods I normally eat to eat more vegetables (MO) & 0.87 & \multirow[t]{4}{*}{6.6} & \multirow[t]{4}{*}{0.78} \\
\hline & I would consider cutting out foods I normally eat to eat more fruit (MO) & 0.84 & & \\
\hline & I would eat more fruit and vegetables in order to lose weight (MO) & 0.68 & & \\
\hline & I would eat more fruit and vegetables in order to protect myself against cancer (MO) & 0.57 & & \\
\hline \multirow[t]{2}{*}{ Organic } & I would like to eat more organic fruit (AF) & 0.92 & \multirow[t]{2}{*}{6.2} & \multirow[t]{2}{*}{0.98} \\
\hline & I would like to eat more organic vegetables (AF) & 0.92 & & \\
\hline \multirow[t]{4}{*}{ Transport } & I often use taxis to get my shopping home (AC) & 0.71 & \multirow[t]{4}{*}{5.3} & \multirow[t]{4}{*}{0.55} \\
\hline & I often use my local bus service to get my shopping home (AC) & 0.69 & & \\
\hline & I often get my shopping delivered to my home (AC) & 0.55 & & \\
\hline & My local bus service is affordable (AF) & 0.54 & & \\
\hline
\end{tabular}

(AC) - statement related to the theme 'Access'; (AF) - 'Affordability'; (MO) - 'Motivation'.

${ }^{*}$ Factor loadings and the percentage of variance explained are based on the rotated solution. 
women were more willing than men to consider eating more $\mathrm{F} \& \mathrm{~V}$ to lose weight or protect themselves against cancer and would consider cutting out foods they normally ate to eat more F\&V.

\section{Age}

MANOVA analysis indicated that the age of the participants had influenced attitude scores (Pillai's Trace $F(18,1902)=7.869, \quad P<0.001)$ in particular on the 'Choice', 'Health', 'Change' and 'Transport' sub-scales (Table 4). Participants in increasing age groups were more likely to believe they were eating healthily and enjoyed eating F\&V than the younger groups (Table 4). However, the oldest group (71-100 years) were least likely to consider changing their diet to eat more F\&V. They were also more likely to use public transport than each of the younger groups (Table 4).

\section{Employment}

MANOVA conducted to test the effect of employment status on attitudes towards healthy eating was significantly different across the sub-scales (Pillai's Trace $F(30,2980)=4.666, P<0.001)$. The univariate tests identified that this difference was significant for the 'Health', 'Affordability', 'Change' and 'Transport' subscales (Table 5). Post hoc analysis revealed that participants who were retired more strongly agreed they ate enough F\&V for their health than any of the other groups (Table 5). In addition, participants who were jobseekers believed they had greater difficulties in buying more F\&V than participants who were employed full or part time or retired.

\section{Smoking}

There was a significant difference between smokers, nonsmokers and ex-smokers in their attitudes to healthy eating and access to food (Pillai's Trace $F(12,1248)=3.148$, $P<0.001)$. However, the univariate $F$ was significant only for the 'Health' sub-scale (Pillai's Trace $F(2,628)=35.143$, $P<0.001)$. Post boc analysis revealed that smokers (attitude rating, mean \pm standard deviation $(\mathrm{SD})=$ $2.6 \pm 1.2$ ) were less likely to agree they ate enough F\&V for their health than both non-smokers $(2.1 \pm 1.1$, $P<0.001)$ and ex-smokers (2.2 $\pm 1.1, P<0.001)$.

\section{Marital status}

Attitudes towards healthy eating, access to and affordability of healthy food were significantly different according to marital status (Pillai's Trace $F(18,1878)=$ 6.6, $P<0.001)$. The univariate tests were significant for all six sub-scales (Table 6). Post hoc tests revealed that participants who were single perceived they had less choice in the F\&V they could buy than participants who were married or lived with a partner. In addition, single people were less likely to believe they enjoyed or ate enough F\&V for their health. In contrast, participants who were widowed were most likely to agree they were eating healthily and found F\&V more affordable. Widowed participants were also more likely to use public transport than other groups.

Table 4 Attitude ratings (mean \pm standard deviation) for the effect of age on attitudes towards healthy eating, access and affordability

\begin{tabular}{lccccc}
\hline & \multicolumn{4}{c}{ Age group (years) } \\
\cline { 3 - 6 } & Univariate $F$ & $17-30(n=179)$ & $31-50(n=235)$ & $51-70(n=126)$ & $71-100(n=101)$ \\
\hline Choice & $6.158^{\star \star \star}$ & $2.2 \pm 1.0^{\mathrm{abc}}$ & $1.9 \pm 0.8^{\mathrm{a}}$ & $1.8 \pm 0.9^{\mathrm{b}}$ & $1.8 \pm 0.8^{\mathrm{c}}$ \\
Health & $24.118^{\star \star \star}$ & $2.7 \pm 1.3^{\mathrm{abc}}$ & $2.2 \pm 1.1^{\mathrm{ade}}$ & $2.3 \pm 1.1^{\mathrm{bd}}$ & $1.7 \pm 0.9^{\mathrm{ce}}$ \\
Change & $6.175^{\star \star \star}$ & $3.0 \pm 1.3^{\mathrm{a}}$ & $2.9 \pm 1.3^{\mathrm{b}}$ & $2.8 \pm 1.4^{\mathrm{c}}$ & $3.5 \pm 1.8^{\mathrm{abc}}$ \\
Transport & $11.975^{\star \star \star}$ & $5.6 \pm 1.7^{\mathrm{a}}$ & $5.5 \pm 1.2^{\mathrm{b}}$ & $5.4 \pm 1.4^{\mathrm{c}}$ & $4.8 \pm 1.6^{\mathrm{abc}}$ \\
\hline
\end{tabular}

***, $P<0.001$

Means with the same letter per row are significantly different from one another, $P<0.05$.

Table 5 Attitude ratings (mean \pm standard deviation) for the effect of employment status on attitudes towards healthy eating, access and fordability

\begin{tabular}{|c|c|c|c|c|c|c|c|}
\hline & \multirow[b]{2}{*}{ Univariate $F$} & \multicolumn{6}{|c|}{ Employment status } \\
\hline & & $\begin{array}{c}\text { Employed } \\
\text { full time }(n=111)\end{array}$ & $\begin{array}{c}\text { Employed } \\
\text { part time }(n=97)\end{array}$ & $\begin{array}{l}\text { Jobseeker } \\
(n=69)\end{array}$ & $\begin{array}{l}\text { On sick leave } \\
\quad(n=44)\end{array}$ & $\begin{array}{c}\text { Looking after } \\
\text { family }(n=125)\end{array}$ & $\begin{array}{l}\text { Retired } \\
(n=157)\end{array}$ \\
\hline Health & $12.037^{\star \star \star}$ & $2.5 \pm 1.2^{\mathrm{a}}$ & $2.3 \pm 1.1^{b}$ & $2.4 \pm 1.0^{c}$ & $2.6 \pm 1.4^{d}$ & $2.5 \pm 1.2^{\mathrm{e}}$ & $1.7 \pm 0.9^{\mathrm{abcde}}$ \\
\hline Affordability & $4.601^{\star \star \star}$ & $3.6 \pm 1.6^{\mathrm{a}}$ & $3.3 \pm 1.7^{b}$ & $2.5 \pm 1.5^{\mathrm{abc}}$ & $3.0 \pm 1.5$ & $3.1 \pm 1.5$ & $3.4 \pm 1.7^{c}$ \\
\hline Change & $2.948^{*}$ & $3.1 \pm 1.3$ & $2.9 \pm 1.3$ & $2.8 \pm 1.4$ & $2.8 \pm 1.2$ & $2.7 \pm 1.3^{\mathrm{a}}$ & $3.2 \pm 1.6^{\mathrm{a}}$ \\
\hline Transport & $12.198^{\star \star \star}$ & $5.7 \pm 1.2^{\mathrm{a}}$ & $5.6 \pm 1.2^{\mathrm{b}}$ & $5.3 \pm 1.4$ & $5.7 \pm 1.3^{\mathrm{c}}$ & $5.5 \pm 1.2^{\mathrm{d}}$ & $4.9 \pm 1.5^{\mathrm{abcd}}$ \\
\hline
\end{tabular}

${ }^{\star}, P<0.05 ;{ }^{\star \star \star}, P<0.001$

Means with the same letter per row are significantly different from one another, $P<0.05$ 
Table 6 Attitude ratings (mean \pm standard deviation) for the effect of marital status on attitudes towards healthy eating, access and affordability

\begin{tabular}{lccccc}
\hline & \multicolumn{4}{c}{ Marital status } \\
\cline { 3 - 6 } & Univariate $F$ & $\begin{array}{c}\text { Single } \\
(n=178)\end{array}$ & $\begin{array}{c}\text { Married/with partner } \\
(n=212)\end{array}$ & $\begin{array}{c}\text { Divorced/separated } \\
(n=155)\end{array}$ & $\begin{array}{c}\text { Widowed } \\
(n=68)\end{array}$ \\
\hline Choice & $3.486^{\star}$ & $2.1 \pm 0.9^{\mathrm{a}}$ & $1.8 \pm 0.7^{\mathrm{a}}$ & $2.0 \pm 0.9$ & $1.8 \pm 0.9$ \\
Health & $15.715^{\star \star \star}$ & $2.7 \pm 1.3^{\mathrm{abc}}$ & $2.2 \pm 1.1^{\mathrm{ad}}$ & $2.3 \pm 1.1^{\mathrm{be}}$ & $1.7 \pm 0.9^{\mathrm{cde}}$ \\
Affordability & $5.457^{\star \star \star}$ & $3.0 \pm 1.5^{\mathrm{a}}$ & $3.4 \pm 1.6^{\mathrm{ab}}$ & $2.9 \pm 1.5^{\mathrm{bc}}$ & $3.5 \pm 1.7^{\mathrm{c}}$ \\
Change & $5.507^{\star \star \star}$ & $3.0 \pm 1.3^{\mathrm{a}}$ & $2.9 \pm 1.3^{\mathrm{b}}$ & $2.8 \pm 1.4^{\mathrm{c}}$ & $3.5 \pm 1.8^{\mathrm{abc}}$ \\
Organic & $4.651^{\star *}$ & $3.0 \pm 1.9^{\mathrm{a}}$ & $3.8 \pm 1.9^{\mathrm{a}}$ & $3.3 \pm 2.1$ & $3.3 \pm 1.9^{\mathrm{abc}}$ \\
Transport & $7.995^{\star \star *}$ & $5.6 \pm 1.7^{\mathrm{a}}$ & $5.5 \pm 1.2^{\mathrm{b}}$ & $5.4 \pm 1.4^{\mathrm{c}}$ & $4.8 \pm 1.6^{\mathrm{bbc}}$ \\
\hline
\end{tabular}

${ }^{\star}, P<0.05 ;{ }^{* \star}, P<0.01 ;{ }^{\star \star \star}, P<0.001$.

Means with the same letter per row are significantly different from one another, $P<0.05$

\section{Access to food}

Forty-five per cent of respondents had no access to a car for shopping; another indicator of the poverty level in this group (Table 7). The participants who did not have access to a car tended to be jobseekers, on sick leave or retired and widowed (Table 8). Of the participants who did not have access to a car, $71 \%$ still thought visiting a supermarket was easy to do. In fact, $90 \%$ of all participants did their food shopping in a large supermarket and $79 \%$ of participants shopped once or more than once a week. Twenty-three per cent regularly used the local bus service for food shopping, 15\% used taxis and 10\% had their shopping delivered. Forty-four per cent of participants without a car thought the bus was affordable while $20 \%$ did not. Of those who did not have access to a car (45\%), only $32 \%$ claimed to eat 5 or more portions of $\mathrm{F} \& \mathrm{~V}$ (Table 8 ) and yet $72 \%$ still believed they ate healthily.

Table 9 describes selected responses made to questionnaire items concerning issues of access to and affordability of fruits and vegetables and motivation to eat healthily. The categories neither agree nor disagree and slightly agree/disagree were excluded in order to simplify the table to show the tendencies of positive or negative attitudes. Very few people complained about the choice of fresh, frozen or tinned F\&V available or about the choice of shops available in their local area. Less than $10 \%(n=50)$ voiced a problem in getting to a supermarket. Of those few who did find it difficult visiting a

Table 7 Participant characteristics related to food shopping

\begin{tabular}{lcc}
\hline Characteristic & Frequency & \% of total \\
\hline Access to a car for shopping purposes & 362 & \\
Access to a car & 298 & 45 \\
No car available & & \\
Shop & 571 & 90 \\
$\quad$ Large supermarket & 48 & 7 \\
Local store & 18 & 3 \\
Other & & \\
Frequency of shopping & 80 & 12 \\
Once every two weeks & 278 & 42 \\
Once a week & 261 & 39 \\
More than once a week & 43 & 7 \\
Other (e.g. daily) & & \\
\hline
\end{tabular}

supermarket, five people lived in a rural location. The remainder of participants who did have difficulty in visiting a supermarket tended to be the elderly.

Location of the participant's house had an impact on their desire to eat more organic F\&V (Pillai's Trace $F(2,654)=4.963, P<0.01)$. Post hoc analysis showed that participants living in rural areas (attitude rating, mean $\pm \mathrm{SD}=4.0 \pm 1.9$ ) were less likely to want to eat more organic F\&V than those living in urban areas (3.2 \pm 2.0). Twenty-five per cent of participants who lived in urban areas claimed to eat organic food while only $14 \%$ of those living in rural areas did.

\section{Affordability}

It might be assumed that, for low-income consumers, the cost of healthy foods would represent a large barrier to healthy eating. However, two-thirds of participants did not think that lack of money prevented them from eating a

Table 8 Selected questionnaire responses for participants with or without access to a car for shopping purposes

\begin{tabular}{lcc}
\hline $\begin{array}{l}\text { Characteristic } \\
\text { \% With a car }\end{array}$ & $\begin{array}{c}\text { \% Without } \\
\text { a car }\end{array}$ \\
\hline $\begin{array}{l}\text { Number of portions of F\&V claimed to be eaten } \\
0-2\end{array}$ & 55 & 45 \\
$3-4$ & 48 & 45 \\
$5+$ & 68 & 52 \\
Location & & 32 \\
Urban & 50 & \\
Suburban & 62 & 50 \\
Rural & 73 & 38 \\
Employment status & & 27 \\
Full time & 68 & \\
Part time & 71 & 32 \\
Jobseeker & 26 & 29 \\
Looking after family & 60 & 74 \\
Retired & 40 \\
On sick leave & 46 & 54 \\
Marital status & 44 & 56 \\
Single & & \\
Married/with partner & & 59 \\
Divorced/separated & 41 & 20 \\
Widowed & 42 & 58 \\
\hline
\end{tabular}

F\&V - fruit and vegetables. 
Table 9 Selected questionnaire responses relating to issues of access, affordability and motivation to eat healthily

\begin{tabular}{lrr}
\hline Question & $\begin{array}{c}\text { \% Strongly/moderately } \\
\text { agree }\end{array}$ & $\begin{array}{c}\text { \% Strongly/moderately } \\
\text { disagree }\end{array}$ \\
\hline Where I shop has a wide choice of fresh fruit/vegetables* & 88.3 & 1.1 \\
There is a wide choice of food shops in my local area & 57.6 & 7.5 \\
Visiting a supermarket is easy for me to do & 76.5 & 7.4 \\
I think fruit/vegetables* are affordable to me in the shop where I buy most of my food & 53.5 & 3.5 \\
Buying more fruit/vegetables* would be difficult on my budget & 33.8 & 7.5 \\
Lack of money prevents me from eating healthily & 57.6 & 29.5 \\
l eat healthily & 61.9 & 4.0 \\
l eat enough fruit for my health & 10.0 \\
I eat enough vegetables for my health & 7.2 \\
\hline
\end{tabular}

${ }^{*}$ Percentage calculated as a mean of combined responses to separate questions regarding fruits and vegetables.

healthy diet and in fact $73 \%$ of participants strongly or moderately believed they ate healthily anyway (Table 9) (see 'Motivation to eat healthily'). Of the remaining $27 \%$ who did not strongly/moderately believe they were eating healthily, less than half (45\%) of them also thought that lack of money prevented them from eating healthily. Among this group, lack of money to eat healthily was a particular issue for participants who were jobseekers (65\%) or on sick leave $(69 \%)$.

Over three-quarters thought that F\&V were reasonably priced where they shopped and less than 5\% complained about the price of F\&V (Table 9). Yet paradoxically, over half thought that buying more $\mathrm{F} \& \mathrm{~V}$ would be difficult due to costs; these people tended to be currently jobseekers (Tables 5 and 9). In fact, $67 \%$ of participants who were jobseekers thought that buying more F\&V was prohibitively expensive compared with $41 \%$ of those in full-time employment. Those participants who claimed to eat $0-2$ portions were most likely to believe they could not afford to buy more F\&V. In other words, it appears that these consumers are able to budget for the amount of F\&V they buy habitually, which for most is at a reasonable price, but are unwilling or unable to purchase more than this habitual amount.

\section{Motivation to eat healthily}

A MANOVA conducted to investigate the effect of the number of portions of $F \& V$ participants claimed to eat on attitudes to eating healthily was significantly different across the sub-scales (Pillai's Trace $F(12,1262)=16.123$, $P<0.001)$. The univariate tests identified that this difference was significant for the 'Choice', 'Health', 'Affordability' and 'Organic' sub-scales (Table 10). Post hoc tests revealed that participants claiming to eat just $0-2$ portions of F\&V per day perceived they had less choice than those claiming to eat 5 or more (Table 10). Nearly three-quarters of the participants believed they ate healthily (Table 9) and yet $82 \%$ claimed to eat 4 or fewer portions of F\&V per day (Table 2). The greater the number of portions of $F \& V$ participants professed to eat, the greater they agreed that they were eating healthily and also agreed they would like to eat more organic food.
Cross-tabulation analyses using Pearson's $\chi^{2}$ statistic identified that the number of portions claimed to be eaten by the participants was related to gender $\left(\chi^{2}(2)=10.177\right.$, $P<0.01)$, age $\left(\chi^{2}(6)=40.206, \quad P<0.001\right)$, smoking $\left(\chi^{2}(4)=32.474, \quad P<0.001\right)$, marital status $\left(\chi^{2}(6)=\right.$ 15.669, $P<0.001)$ and employment $\left(\chi^{2}(10)=28.297\right.$, $P<0.01)$. Those claiming to eat the recommended 5 portions of F\&V tended to be in the age group 51-70 years, and were mostly women and widowed, while those claiming to eat just $0-2$ portions tended to be young, single, male, smokers and jobseekers. This is consistent with the view that people who make one 'unhealthy' lifestyle choice, for example smoking, are more likely to take others such as eating a poor diet ${ }^{27}$.

One-third of the participants who claimed that they ate 5 or more portions per day also ate organic fruits and vegetables, compared with $24 \%$ in the group who claimed to eat 3-4 portions and $16 \%$ in the $0-2$ portions group.

\section{Discussion}

People on low incomes tend to consume less F\&V than higher-income groups and this is believed to contribute to the current social health inequalities ${ }^{7,8}$. The UK Government has specifically targeted LIGs as part of its public health campaign to increase fruit and vegetable consumption. Supported by research, the Government's policy is driven by the belief that LIGs have difficulties in access to and affordability of F\&V. On the basis of findings from a

Table 10 Attitude ratings (mean \pm standard deviation) for the number of portions of fruit and vegetables (F\&V) participants claim to eat

\begin{tabular}{lcccc}
\hline & \multicolumn{3}{c}{ Number of F\&V portions } \\
\cline { 3 - 5 } & & $\begin{array}{c}0-2 \\
(n=317)\end{array}$ & $\begin{array}{c}3-4 \\
(n=207)\end{array}$ & $\begin{array}{c}5+ \\
(n=114)\end{array}$ \\
\hline Choice & $5.337^{\star \star}$ & $2.0 \pm 0.9^{\mathrm{a}}$ & $1.9 \pm 0.9$ & $1.7 \pm 0.7^{\mathrm{a}}$ \\
Health & $78.876^{\star \star \star}$ & $2.8 \pm 1.2^{\mathrm{ab}}$ & $2.0 \pm 0.9^{\mathrm{ac}}$ & $1.5 \pm 0.7^{\mathrm{bc}}$ \\
Affordability & $10.737^{\star \star *}$ & $3.0 \pm 0.6^{\mathrm{a}}$ & $3.2 \pm 1.5^{\mathrm{b}}$ & $3.8 \pm 1.8^{\mathrm{ab}}$ \\
Organic & $5.807^{\star \star}$ & $3.5 \pm 2.0^{\mathrm{a}}$ & $3.5 \pm 1.9^{\mathrm{b}}$ & $2.8 \pm 1.9^{\mathrm{ab}}$ \\
\hline
\end{tabular}

${ }^{* *}, P<0.01 ;{ }^{* * *}, P<0.001$

Means with the same letter are significantly different from one another, $P<0.01$. 
previous in-depth qualitative study ${ }^{24}$, we have addressed the issues of access to and affordability of fruits and vegetables, together with motivation to eat these foods, within a large LIG cohort of a UK housing association. Findings from these three issues will now be discussed in turn.

\section{Accessibility issues}

Access has been defined as 'being able to obtain a variety of healthy foods at a reasonable price ${ }^{14}$ and is seen as a major obstacle for LIGs. On face value, access to a car for shopping purposes does seem to support the view that ease of transport enables people to eat more $F \& V$ (Table 8). However, the situation is much more complex. Possession of a car relates to a combination of demographic variables: employment and marital status, age, location and income. Physical access to a large supermarket did not appear to be a problem for this low-income subgroup in this region, despite the fact that nearly half of the participants did not have access to a car for shopping purposes. This may seem a surprising result, but confirms our previous qualitative study ${ }^{24}$. The participants in this study had managed to overcome their difficulties with transport in order to gain necessary access to food. In fact, $90 \%$ of participants stated they did most of their shopping in a large supermarket, although perhaps this is a symptom of supermarket monopoly. Less than $10 \%$ of participants complained about the choice of fresh, frozen or tinned produce in the shop where they bought most of their food and the vast majority ( $>90 \%$ ) agreed that there were adequate shopping facilities local to them. However, those few participants who did express a problem with access to a supermarket should not be ignored.

The problem of accessibility of wholesome foods is also directly linked to the competing accessibility of energydense nutrient-poor products and, as highlighted by others, the promotion and availability of these products far exceed that for fruits and vegetables for example ${ }^{7}$. The prevalence and nature of accessibility issues therefore need to be established. If, for example, physical access to wholesome foods is not such an issue to healthy eating, as suggested by the results of this study, then we need to identify what the main barriers are.

\section{Affordability issues}

Low-income groups traditionally spend proportionally more of their income on food than higher-income groups $^{13}$. Some of our findings would, on first appearance, tend to support the current belief that lack of money was a barrier to eating F\&V for our participants. However, there were many contradictions in participants' responses with respect to affordability of F\&V. For example, 34\% said that lack of money prevented them from eating healthily, but only $4 \%$ disagreed with the statement that they eat healthily. Perhaps people are more likely to cite 'lack of money' as a barrier to obtaining healthy foods than to consider more complex explanations. Jobseekers (11\%) particularly felt that buying more F\&V was too expensive, but only $4 \%$ of the entire sample thought that $F \& V$ were not affordable to them in the shop where they bought most of their food.

Those participants claiming to eat the fewest $(0-2)$ portions of $F \& V$ per day felt that buying more $F \& V$ would be difficult on their budget. However, the same was true for participants who ate more than 3 portions of $F \& V$ per day. In other words, most participants had managed their budget to purchase their habitual amounts of $\mathrm{F}^{2} \mathrm{~V}^{28}$, but considered purchasing more $\mathrm{F} \& \mathrm{~V}$ as an additional expense, rather than exchanging usual food items for healthier options. This is consistent with the notion that buying 'more' of something seems to be a significant psychological barrier ${ }^{25}$, and was also highlighted in our qualitative study ${ }^{24}$.

Although LIGs in the UK eat on average 2.7 portions ${ }^{11}$, it is important to note that higher-income groups also do not eat the recommended 5 or more portions of F\&V every day $^{11}$. Indeed, a study examining what happens to people's food choices when their income changes found that 'an increase in income did not necessarily lead to increased expenditure on food no improved diet quality overall $^{13}$. Thus low fruit and vegetable intakes cannot solely be a factor of income.

\section{Motivation to eat bealtbily}

The majority of participants $(>70 \%)$ believed that they were already eating healthily and yet only 18\% were claiming to eat the recommended 5 or more portions of F\&V daily. Considering this survey was distributed in the summer when people generally eat more F\&V anyway, this is a surprisingly low figure. This highlights a fundamental barrier to promoting healthy food choices and is symptomatic of the population as a whole. Without acknowledging that a problem exists, it is difficult to effect a conscious behavioural change. Many would argue that it is simply a matter of raising awareness about healthy eating. However, people already generally understand what healthy eating is, albeit mostly at a semi-quantitative level $^{29}$. According to a recent Food Standards Agency survey, $50 \%$ of participants now know the recommendations for fruit and vegetable intakes and yet it is clear from national data that few people actually achieve this target: currently the average UK consumption of F\&V is 3 portions per day ${ }^{26}$. So, if awareness is not the key factor in motivating people to eat healthily, there must be some other cause.

In addition, the primary purpose of eating a healthy diet, as well as providing adequate nutrition for today's needs, is to prevent diseases such as cancer, heart disease and obesity-related problems such as diabetes in the future. However, the tendency for LIGs to be past- and present-oriented ${ }^{30}$ may reduce their desire to engage in preventive health behaviours. Elderly people in particular 
may have developed habitual actions with respect to diet ${ }^{28}$ and their present orientation and unrealistic optimism over the future ${ }^{31}$ would make them unwilling to change their diets to prevent possible future diseases.

The issue of doing more of something is in direct contrast to many health improvement campaigns, which require the reduction of a lifestyle activity ${ }^{25}$. This often means denying oneself pleasures in some way, such as stopping smoking or reducing fat, alcohol or salt intake. The smoking cessation campaign highlights the financial savings that could be made as a result of quitting, whereas eating more F\&V will automatically be viewed as an additional expense in terms of cost, physical and psychological effort and time. This was again confirmed by our interview findings ${ }^{24}$. Campaigns to promote eating more F\&V may therefore be accompanied by education on ways to exchange habitually bought food items for F\&V such that no further expense, in money or effort, is incurred.

In summary, this study highlights the complexity of the food poverty issue. This complexity needs to be taken into account when defining food poverty and especially when developing strategies to address the problem. The findings from this LIG revealed that access to F\&V was not a major barrier to eating healthily and affordability of F\&V was more complex than simply a lack of money. Indeed, other factors - such as motivational, psychosocial or lifestyle factors - presented bigger barriers. Thus, there is a danger of blaming difficulties in access and affordability for LIGs eating an unhealthy diet. This may be true for some individuals in LIGs, but the extent of this simplistic view across all UK LIGs is not clear. This study should therefore be easily transferable to other housing associations in different regions across the UK.

While one is always supportive of resourced strategies to address the issue of relative poverty in the UK, the targeting of LIGs regarding unhealthy diets, although welcome in some respects, does introduce the possible danger of stigmatising LIGs as unhealthy eaters, as was the case 20 years ago ${ }^{32}$. As our previous study ${ }^{24}$ (and others) has shown, not all people on low incomes eat inappropriate diets. Surveys show that over three-quarters of people in the UK do not eat the recommended amounts of $F \& V^{11,26}$ and thus the problem is clearly more widespread than in one demographic group. Distribution curves plotting portions of $F \& V$ eaten against number of consumers for various sectors of society would indicate that one could arbitrarily choose many different societal polarities for 'targeting' (for example, the young, males and especially smokers all tend to consume low amounts of F\&V). However, for this type of public health problem it has been argued that 'targeting' is an ineffective strategy and one should consider the population as a whole ${ }^{33}$. One would not want to see limited resources used to combat access and affordability difficulties in areas where these are not the major barriers.

\section{Acknowledgements}

The authors would firstly like to thank the tenants and staff of Broadland Housing Association for their co-operation and support. The authors would also like to thank Dr Susan Miles for her invaluable advice on the statistical analysis for this study. The authors receive funding from the Biotechnology and Biological Sciences Research Council.

\section{References}

1 Committee on Diet and Health, Food and Nutrition Board, National Research Council. Diet and Health: Implications for Reducing Chronic Disease Risk. Washington, DC: National Academy Press, 1989.

2 Ferro Luzzi A, Gibney M, Sjöström M, eds. Nutrition and diet for healthy lifestyles in Europe: the EURODIET evidence [special issue]. Public Health Nutr. 2001: 4(2A): 437-740.

3 World Health Organization (WHO). Diet, Nutrition and the Prevention of Chronic Diseases. Report of a WHO Study Group. Technical Report Series No. 797. Geneva: WHO, 1990.

4 Cummings JH, Bingham SA. Diet and the prevention of cancer. Br. Med. J. 1998; 317: 1636-40.

5 Department of Health. The NHS Cancer Plan. London: The Stationery Office, 2000.

6 Lambert N. Food choice, phytochemicals and cancer prevention. In: Frewer L, Risvik E, Schifferstein H, eds. Food, People and Society. A European Perspective of Consumers' Food Choices. Berlin: Springer-Verlag, 2001; $131-54$.

7 Leather S. Fruit and vegetables: consumption patterns and health consequences. Br. Food J. 1997; 7: 10-7.

8 Lobstein T. Health, income and diet. In: Tackling Inequalities in Health and Diet Related Disease. Sustain Publication. London: KKS Printing, 1999

9 Billson H, Pryer JA, Nichols R. Variation in fruit and vegetable consumption among adults in Britain. An analysis from the dietary and nutritional survey of British adults. Eur. J. Clin. Nutr. 1999; 53: 946-52.

10 Department of Health. The NHS Plan: A Plan for Investment, A Plan for Reform. London: The Stationery Office, 2000.

11 Department of Health. National Food Survey. London: The Stationery Office, 2001.

12 Dowler E, Draper A, Nelson M, Thomas R, Dobson B. Scoping study for a proposed national dietary and nutritional survey of people living on low incomes in the UK. Ministry of Agriculture, Fisheries and Food Report No. An1060, 1998.

13 Shepherd R, Paisley CM, Sparks P, Anderson AS, Eley S, Lean MEJ. Constraints on dietary choice: the role of income. Nutr. Food Sci. 1996; 5: 19-21.

14 Donkin AJM, Dowler EA, Stevenson SJ, Turner SA. Mapping access to food in a deprived area: the development of price and availability indices. Public Health. Nutr. 2000; 3: 31-8.

15 Brug J, Lechner L, De Vries H. Psychosocial determinants of fruit and vegetable consumption. Appetite 1995; 25: 285-96.

16 National Food Alliance. Myths About Food and Low Income. London: National Food Alliance Publication, 1997.

17 Webster J. Developing Local Networks to Tackle Food Poverty. London: Sustain, 1999.

18 McGlone P, Dobson B, Dowler E, Nelson M. Food Projects and How They Work. York: Joseph Rowntree Foundation Publication, 1999.

19 Dowler E, Blair A, Donkin A, Rex D, Grundy C. Measuring access to healthy food in Sandwell. Sandwell Health Action 
Zone Final Report. Sandwell: Sandwell Health Authority, June 2001.

20 Aston-Mansfield and Newham NHS Primary Care Trust. The right to a healthy diet: sustaining the fight against food poverty [online]. Available at http://www.nfap.org.uk/ Right_to_a_healthy_diet.pdf. London: Newham Food Access Partnership, 2001

21 Kennedy LA, Hunt C, Hodgson P. Nutrition education program based on EFNEP for low-income women in the United Kingdom: 'Friends with Food'. J. Nutr. Educ. 1998; 30: 89-99.

22 Chapman H, Kendall PA. Twenty years of EFNEP: changes and challenges. J. Nutr. Educ. 1989; 21: 6.

23 Department for Transport, Local Government and the Regions. Statistics, 2001 [online]. Available at http://www. housing.detr.gov.uk.

24 Dibsdall LA, Lambert N, Frewer LJ. Using interpretative phenomenology to understand the experiences of a lowincome group of UK women towards aspects of food choice and health. J. Nutr. Educ. 2002; 34: 298-309.

25 Lambert N, Dibsdall LA, Frewer LJ. Poor diet and smoking: the big killers. Comparing health education in two hazard domains. Br. Food J. 2002; 104: 63-75.
26 Food Standards Agency. Consumer Attitudes to Food Standards. London: The Stationery Office, 2002.

27 Glanz K, Basil M, Maibach E, Goldberg J, Snyder D. Why Americans eat what they do: taste, nutrition, cost, convenience, and weight control concerns as influences on food consumption. J. Am. Diet. Assoc. 1998; 98: 1118-26.

28 Aarts H, Verplanken B, Van Knippenberg A. Predicting behaviour from actions in the past: repeated decision making or a matter of habit? J. Appl. Soc. Psych. 1998; 28 1355-74.

29 Povey R, Conner M, Sparks P, James R, Shepherd R. Interpretations of healthy and unhealthy eating, and implications for dietary change. Health Educ. Res. 1998; 13: $171-83$

30 Bergadaà MM. The role of time in the action of the consumer J. Consumer Res. 1990; 17: 289-302.

31 Lennings CJ. Optimism, satisfaction and time perspective in the elderly. Int. J. Aging Hum. Dev. 2000; 51: 167-81.

32 Trowler P. Investigating Health, Welfare and Poverty, 2nd ed. London: Harper Collins Publishing, 1996; 48-69.

33 Marmot MG. Improvement of social environment to improve health. Lancet 1998; 351: 57-60. 